\title{
ARTICLE Embryonic stem cell transplants as a therapeutic strategy in a rodent model of autism
}

\author{
Jennifer J. Donegan ${ }^{1}$, Angela M. Boley ${ }^{1}$ and Daniel J. Lodge (iD) ${ }^{1}$
}

Autism is a neurodevelopmental disorder characterized by disruptions in three core behavioral domains: deficits in social interaction, impairments in communication, and repetitive and stereotyped patterns of behavior or thought. There are currently no drugs available for the treatment of the core symptoms of ASD and drugs that target comorbid symptoms often have serious adverse side effects, suggesting an urgent need for new therapeutic strategies. The neurobiology of autism is complex, but converging evidence suggests that ASD involves disruptions in the inhibitory GABAergic neurotransmitter system. Specifically, people with autism have a reduction in parvalbumin (PV)-containing interneurons in the PFC, leading to the suggestion that restoring interneuron function in this region may be a novel therapeutic approach for ASD. Here we used a dual-reporter embryonic stem cell line to generate enriched populations of PV-positive interneurons, which were transplanted into the medial prefrontal cortex (mPFC) of the Poly I:C rodent model of autism. PV interneuron transplants were able to decrease pyramidal cell firing in the mPFC and alleviated deficits in social interaction and cognitive flexibility. Our results suggest that restoring PV interneuron function in the MPFC may be a novel and effective treatment strategy to reduce the core symptoms of autism.

Neuropsychopharmacology (2018) 43:1789-1798; https://doi.org/10.1038/s41386-018-0021-0

\section{INTRODUCTION}

Autism spectrum disorders (ASD) are characterized by deficits in social interaction, impairments in communication, and stereotyped patterns of behavior [1]. This heterogeneous group of disorders affects approximately 1 in every 100 U.S. children [2], yet there are no drugs currently available for the treatment of ASD. Rather, pharmacological interventions only target comorbid symptoms, and often have serious adverse side effects [3]. Therefore, new therapeutic strategies targeting the core behavioral deficits associated with ASD are urgently needed.

The etiology of ASD is complex but converging evidence from genetic, post-mortem, imaging, and preclinical studies suggest that ASD may involve dysfunction of the GABAergic system [4]. Autism is highly heritable, and copy number variants have been identified on the 15q11-q13 chromosome, a locus that contains genes related to GABA function, including multiple $G A B A_{A}$ receptor subunits $[5,6]$. Furthermore, mutations in other genes associated with ASD, such as CNTNAP2 and PLUAR, have been shown to decrease the number of GABAergic interneurons in the cortex [4]. Post-mortem and imaging studies in people with autism demonstrate reductions in the $G A B A_{A}$ receptor [7, 8], the GABA synthesizing enzymes, GAD65 and GAD67 [9], and in GABA itself [10]. These deficits seem to be prevalent in the parvalbumin (PV)-containing interneuron subtype. A recent analysis of multiple genetic and environmental mouse models of autism suggests that these animals have reduced numbers of PV-positive interneurons [11]. Furthermore, in mice, PV knockdown produces an autism-like phenotype, resulting in reduced ultrasonic vocalizations, impaired social interaction, and deficits in reversal learning [12]. Recent postmortem studies demonstrate that the percentage of PV-positive interneurons is decreased in prefrontal brain regions of autistic people [13, 14].

PV-positive interneurons critically regulate cortical function by influencing pyramidal cell excitability and coordinating synchronized network activity $[15,16]$. Interestingly, deficits in coordinated activity and hyper-excitability have been observed in the valproic acid model of autism [17] and in some people with autism $[17,18]$. Specifically, dysregulation of the prefrontal cortex (PFC) is consistently observed in ASD [19] and animal models demonstrate that this dysregulated PFC activity can actually cause autism-like behaviors. For example, people with autism show hyperactivity in frontal brain regions [20-22] and elevating the excitation/ inhibition ratio in the PFC of rodents reduces social interaction, a core feature of autism [16]. Furthermore, PV-positive interneurons are both necessary and sufficient to evoke gamma oscillations $[15,23]$ and some people with autism show reductions in synchronized cortical activity, specifically in the gamma frequency range $(30-90 \mathrm{~Hz})[17,24]$. Increasing gamma oscillations in the PFC of rodents increases social interaction time [16] and reduces cognitive inflexibility [25]. Altogether, these results suggest that the GABAergic deficits associated with ASD may result in dysregulated activity in the PFC, and ultimately contribute to the core symptoms of autism.

Cell-based therapies have received much attention for their potential to treat a variety of complex neurological disorders. Interneuron precursors have the unique ability to survive, migrate, and integrate into the cortical circuitry, and display a GABAergic phenotype after transplantation into the brain [26]. It has been shown previously that a dual-reporter mouse embryonic stem cell line can be used to produce enriched populations of PV-positive interneurons [27], and we have recently demonstrated that this

1Department of Pharmacology and Center for Biomedical Neuroscience, University of Texas Health Science Center, San Antonio, TX 78229, USA
Correspondence: Jennifer J. Donegan (Noy@uthscsa.edu)

Received: 9 January 2017 Revised: 9 January 2018 Accepted: 23 January 2018

Published online: 7 February 2018 
approach may be used to restore aberrant hippocampal function in a rodent model of schizophrenia [28]. In the current experiment, we tested the hypothesis that interneuron transplants in the prefrontal cortex would also be effective in autism, a disorder that shares multiple etiological and pathological features with schizophrenia. Maternal viral infection in the first trimester is a risk factor for autism [29]. Therefore, we used polyinosine:cytosine (Poly I:C), a double-stranded RNA, to evoke an antiviral-like immune reaction in pregnant dams. When injected early in gestation (gestational day 12), offspring have been shown to exhibit autism-like deficits in social interaction, communication, and repetitive behaviors [30]. Therefore, in the current experiments, we injected PV interneuron precursors into the mPFC of Poly I:C-treated animals to test the hypothesis that interneuron transplants can normalize dysregulated cortical activity and reverse behavioral deficits relevant to autism.

\section{MATERIALS AND METHODS}

All experiments were performed in accordance with the guidelines outlined in the USPH Guide for the Care and Use of Laboratory Animals and were approved by the Institutional Animal Care and Use Committee of the University of Texas Health Science Center at San Antonio.

\section{Poly I:C Administration}

Timed pregnant female Sprague-Dawley rats were obtained from Harlan on gestational day 11. Poly I:C (Sigma, $7.5 \mathrm{mg} / \mathrm{kg}$, i.p.) or saline was administered on gestational day 12 . The sickness response was monitored in a subset of dams for $72 \mathrm{~h}$ after the injection. Body temperature and food consumption was measured using an anal probe at $0,1,2,3,4,24,48$, and $72 \mathrm{~h}$ after administration, while body weight was recorded at 24,48 , and 72 $\mathrm{h}$ post injection. Male pups were weaned on postnatal day 21 and housed in groups of 3 until they were $>12$-week-old, at which point rats were singly housed and used for behavioral or electrophysiological experiments. All experiments included pups from multiple litters.

\section{Cell Culture}

In order to generate enriched populations of parvalbumin (PV)positive interneurons, we used the $\mathrm{J} 27$ mouse embryonic stem cell line containing dual reporters (Lhx6::GFP and Nkx2.1::mCherry) as previously reported [27]. To differentiate these into interneurons, cells were grown in suspension as embryoid bodies in embryonic stem cell medium containing $1 \% \mathrm{~N} 2$, the BMP inhibitor, LDN$193189(250 \mathrm{nM})$, the Rho-kinase inhibitor, Y27632 $(10 \mu \mathrm{M})$, and the WNT inhibitor, XAV939 $(10 \mu \mathrm{M})$. On differentiation day 3, embryoid bodies were dissociated and plated onto an adherent dish in the presence of fibroblast growth factor-2 $(10 \mathrm{ng} / \mathrm{ml})$ and insulin-like growth factor- $1(20 \mathrm{ng} / \mathrm{ml})$. Media was changed daily until cells were sorted by flow cytometry in the presence of the viability marker, Zombie Violet. PV-enriched populations were sorted for mCherry+ cells on differentiation day 17 as previously reported [28].

\section{Stereotaxic Surgery}

On postnatal days 40-45, animals were anesthetized (sodium pentobarbital, $60 \mathrm{mg} / \mathrm{kg}$, i.p.) and placed in a stereotaxic apparatus. Bilateral cannula aimed at the $\operatorname{mPFC}(\mathrm{A} / \mathrm{P}+3.0, \mathrm{M} / \mathrm{L}$ $\pm 0.6, \mathrm{D} / \mathrm{V}-4.0 \mathrm{~mm}$ from bregma) were used to inject $\sim 40,000$ cells into each hemisphere. To ensure that the behavioral and physiological effects were not due to an inflammatory response caused by the introduction of foreign biological material into the brain, dead cells were used as a control. For dead cell controls, sorted cells were frozen and thawed repeatedly, and a lack of viability was confirmed with trypan blue $[28,31]$. All rats were treated with cyclosporin A (10 mg/kg, s.c.) for 7 days to prevent rejection of mouse embryonic stem cells. After day 7, cyclosporin A was administered in the drinking water $(100 \mu \mathrm{g} / \mathrm{ml})$ for the duration of the experiment. All electrophysiological and behavioral experiments were performed at least 30 days post transplantation, a time point at which the cells have had sufficient time to migrate and integrate into the cortex [27, 28]. Each animal was tested on all the behavioral assays in the following order: ultrasonic vocalizations, social interaction, attention set-shifting test, and prepulse inhibition.

\section{Ultrasonic Vocalizations}

To model the communication deficits observed in autistic children [32], we recorded ultrasonic vocalizations during maternal separation essentially as described in ref. [33]. Briefly, on postnatal day 8 , mothers were removed from the home cage and pups were placed on a $34.5 \mathrm{C}$ heating pad for $15 \mathrm{~min}$. Male and female pups were removed from the cage one at a time and placed in a glass beaker on a $34.5 \mathrm{C}$ heating pad. Ultrasonic vocalizations (USVs) were recorded for $3 \mathrm{~min}$ using an ultrasonic microphone (Dodotronic $200 \mathrm{~K}$ ultramic) placed $\sim 10 \mathrm{~cm}$ above the pup. SeaWave software was used to record USVs at a sampling rate of $192 \mathrm{kHz}$. USVs were counted and expressed as the number of USVs per minute.

\section{Social Interaction}

To model the social deficits observed in people with autism, the Social Interaction Test was performed essentially as described previously [34]. Briefly, rats were placed in a test arena $(100 \times$ $100 \times 40 \mathrm{~cm}$ ) alone for $15 \mathrm{~min}$ per day for 2 days prior to testing. On the test day, experimental rats were placed in the arena with a rat from the same experimental group. The 5 min test was recorded by video camera for offline analysis by a blind experimenter. The dependent measure was the time that the animals spent actively engaged in social interaction, including sniffing, climbing on, following, grooming, or wrestling. In addition, USVs were recorded during the social interaction test and analyzed as described above.

\section{Attentional Set-shifting Test}

To model the deficits in cognitive function that are seen in people with autism, the AST was performed as described [35]. Briefly, rats were restricted to $12 \mathrm{~g}$ food/day for 7 days prior to testing. Using a cheerio reward, rats were trained to dig in pots defined by cues along two stimulus dimensions: the digging medium filling the pot, and an odor applied to the inner rim of the pot. During testing, the rat was taken through a series of stages, each requiring a different discrimination (Fig. 1a), with a criterion of six consecutive correct trials required to proceed to the next stage.

\section{Prepulse Inhibition}

In order to determine whether the therapeutic effects were specific to autism-like deficits, we measured prepulse inhibition of startle (PPI). To measure PPI, rats were placed in sound-attenuated chambers (SD Instruments) and allowed to acclimatize to the 65 $\mathrm{dB}$ background noise for $5 \mathrm{~min}$. Rats were then exposed to the startle-only trials in which a $40 \mathrm{~ms}, 120 \mathrm{~dB}$ pulse was presented 10 times (15 s average inter-trial interval; ITI). Animals were then exposed to 24 trials in which a prepulse was presented $100 \mathrm{~ms}$ before the startle pulse. Prepulses were $20 \mathrm{~ms}$ at $69 \mathrm{~dB}, 73 \mathrm{~dB}$, and $81 \mathrm{~dB}$. Each prepulse + startle pulse and startle pulse only was presented six times in a pseudo-random order ( $15 \mathrm{~s}$ average ITI). The startle response was measured from 10 to $80 \mathrm{~ms}$ after the onset of the startle only pulse and recorded using SR-LAB Analysis Software (SD Instruments). PPI was calculated as a percentage score for each prepulse plus pulse trial type using the following formula: $\% \mathrm{PPI}=\left(100^{*}\right.$ (pulse alone score $)-($ prepulse + pulse score)/pulse alone score)]. 


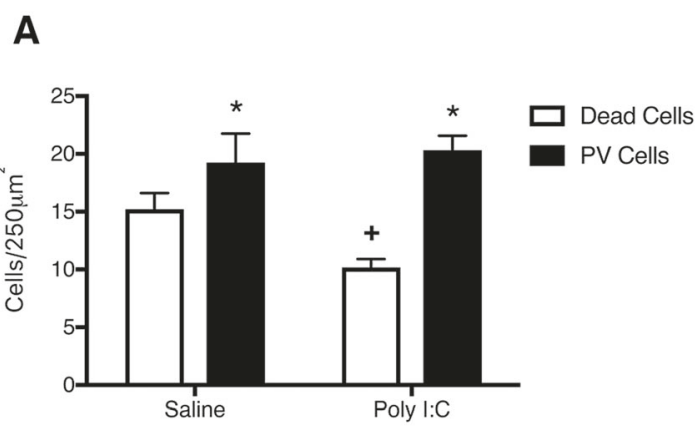

B

D

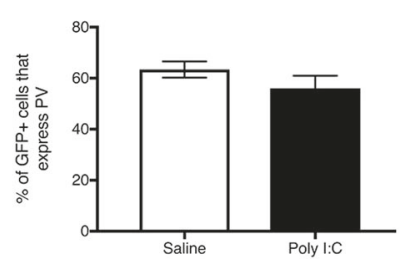

E

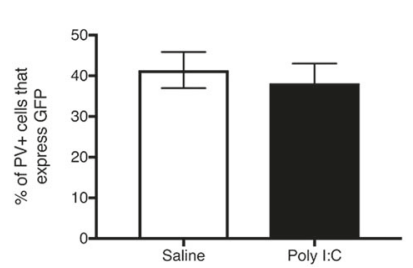

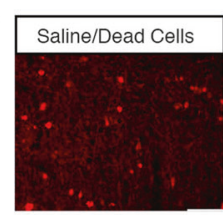
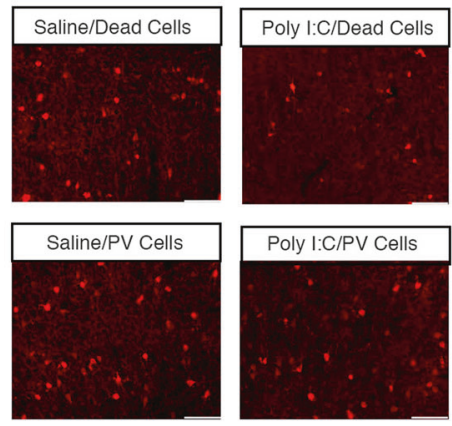

C

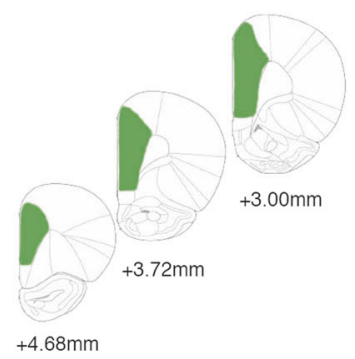

$\mathbf{F}$

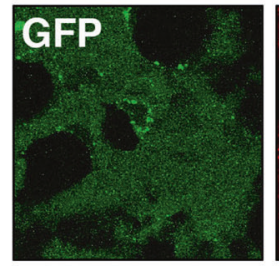

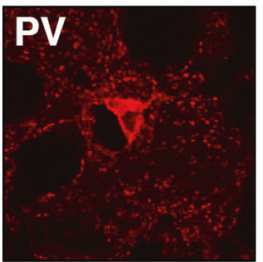

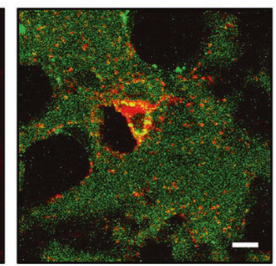

Fig. 1 a Prenatal exposure to Poly I:C on gestational day 12 causes a reduction in the number of PV-positive interneurons in the mPFC of adult offspring. Interneuron transplants increase the number of PV-positive cells in the mPFC in both saline and Poly I:C-treated animals. Representative images of PV-positive cells are shown in $\mathbf{b}$. Embryonic stem cells survive after transplantation into the mPFC and differentiate into an enriched population of PV-positive interneurons. GFP-positive transplants were observed in the $\mathrm{mPFC}$ from $4.68 \mathrm{~mm}$ to $3.00 \mathrm{~mm}$ anterior to Bregma (c). A majority of transplanted cells differentiated into PV-positive interneurons and there was no significant difference in the proportion of GFP-positive cells that expressed PV between saline-treated and Poly I:C-treated animals (d). Approximately 40\% of PVpositive cells in the MPFC also expressed GFP in both saline-treated and Poly I:C-treated rats (e). A representative GFP- and PV-positive interneuron is shown in f. Red is PV and Green is GFP. Scale bar is 100 microns in b and 10 microns in c. ${ }^{*}$ is significantly different than salinetreated controls. $n=4-7$ per group

\section{Extracellular Recordings}

In order to measure pyramidal cell activity, rats were anesthetized with urethane $(1.5 \mathrm{~g} / \mathrm{kg}$, i.p.) and placed in a stereotaxic apparatus. A core body temperature of $37^{\circ} \mathrm{C}$ was maintained as extracellular glass microelectrodes were lowered into the mPFC (A/P + 3.0, M/L $\pm 0.6, \mathrm{D} / \mathrm{V}-3.0$ to -5.0 from bregma). Putative pyramidal neurons in the mPFC were identified by a firing rate between 0.1 and $10 \mathrm{~Hz}$ [36] and were recorded for a period of $3 \mathrm{~min}$. The signal was amplified (×5000) and filtered (low cutoff: $30 \mathrm{~Hz}$; high cutoff: 30 $\mathrm{kHz}$ ) using a Dagan amplifier $2400 \mathrm{~A}$ and analyzed using Labchart software.

\section{Immunohistochemistry}

After behavioral or electrophysiological testing, dual-fluorescence immunohistochemistry was used to determine the number of PVpositive cells in the mPFC. Briefly, rats were transcardially perfused with saline followed by $4 \%$ paraformaldehyde. Brains were postfixed and cryoprotected in $10 \%$ sucrose in phosphate-buffered saline (PBS). Free-floating coronal sections from the mPFC $(50 \mu \mathrm{m})$ were washed in PBS, blocked ( $2 \%$ normal goat serum and $0.3 \%$ Triton X-100), and incubated with rabbit anti-PV (AbCam; 1:1000) antibodies at $4 \mathrm{C}$ overnight. Sections were then incubated with AlexaFluor 594 goat anti-rabbit secondary antibody (1:1000) and mounted on slides and coverslipped using Prolong gold anti-fade reagent with DAPI. Sections from the MPFC (Bregma +3.0 to +4.0 ) were identified using the Paxinos and Watson Brain Atlas [37] and were imaged using an AxioCam ICc 1 (Zeiss) camera attached to an Axio Lab.A1 microscope (Zeiss). The number of PV-positive cells was counted on 4 sections per animal by an experimenter blind to the experimental condition. Labeled cells were counted regardless of fluorescence intensity. The number of PV-positive cells per slice was averaged for each animal.

In a subset of animals, immunohistochemistry was also used to determine the percentage of interneuron transplants that differentiated into PV-positive interneurons. Lhx6 is expressed from the time parvalbumin-positive interneurons exit the cell cycle into adulthood, therefore we used GFP (AbCam; 1:500), which is expressed under the control of Lhx6, to label transplanted cells. The number GFP-positive cells, PV-positive cells, and cells that expressed both GFP and PV were counted on 4 sections per animal by an experimenter blind to the experimental condition. The proportion of GFP cells that were also PV-positive and the proportion of PV cells that were also GFP-positive was expressed as a percentage. The representative images in $1 \mathrm{~F}$ were acquired using an Olympus IX81 Motorized inverted confocal microscope and FV10-ASW software and enhanced using ImageJ.

Data Analysis

In all figures, data are shown as mean + s.e.m and $n$ is indicated in the figure legend.

Data was analyzed by $t$-test, two- or three-way analysis of variance and the Holm-Sidak post hoc test was used when significant interactions were present. All tests were two-tailed, and significance was determined at $p<0.05$.

\section{RESULTS}

Maternal Sickness Behavior

To determine whether the Poly I:C injection produced a sickness response in the pregnant dams, we recorded body temperature, body weight, and food intake for $72 \mathrm{~h}$ after the injection in a subset of rats. We found that there was a small, transient drop in body temperature in the hours following the Poly I:C injection compared to saline-treated controls (Supplementary Figure $1 \mathrm{~A} ; n$ $=2$ rats/group). We also observed a decrease in food intake at 24 $\mathrm{h}$ post injection but by $48 \mathrm{~h}$, there was no difference in food intake between the Poly I:C-treated and saline-treated dams (Supplementary Figure $1 \mathrm{~B} ; n=2$ rats/group). We did not observe a 

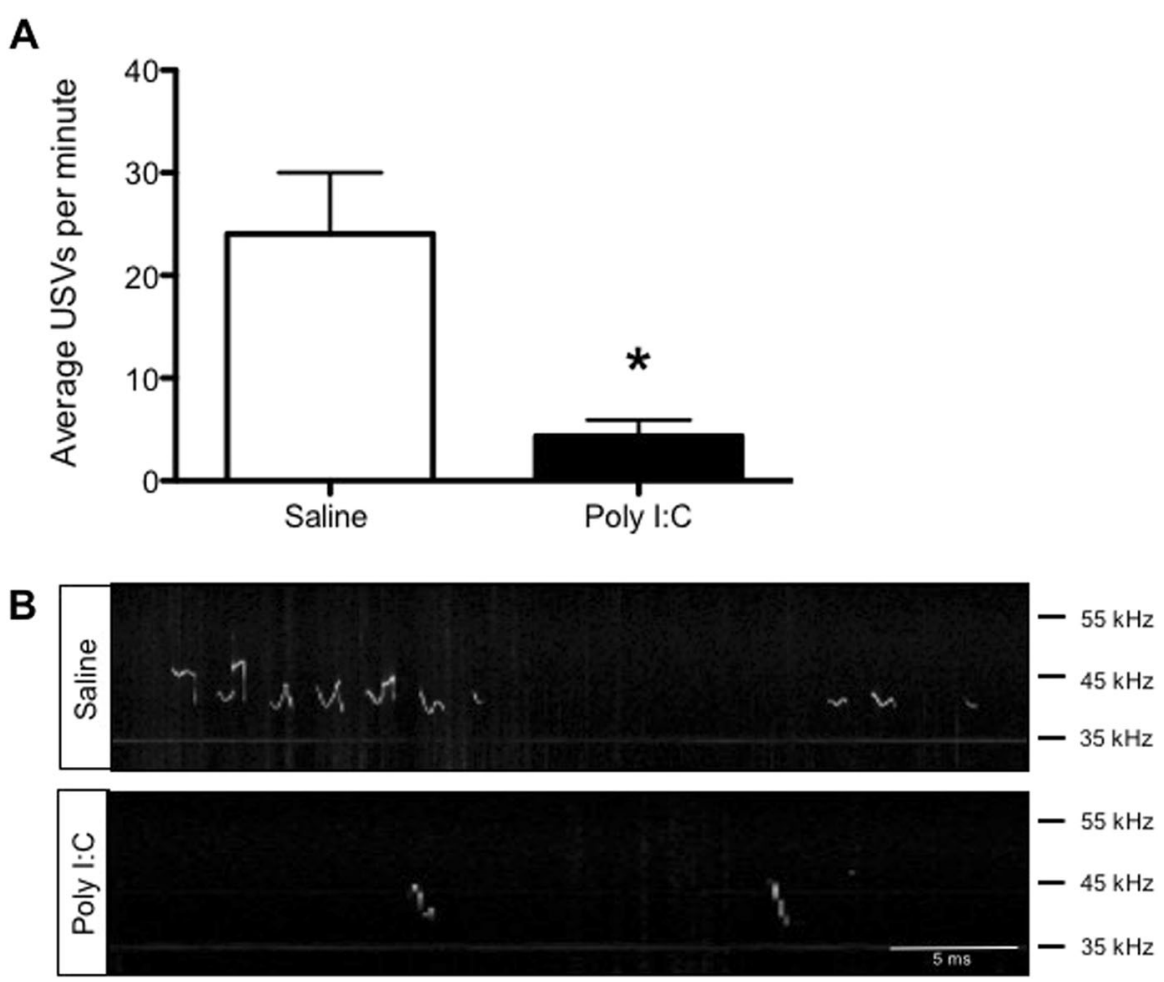

Fig. 2 Prenatal Poly I:C exposure produces deficits in communication. Postnatal day 8 pups exposed to Poly I:C on gestational day 12 produce fewer ultrasonic vocalizations after maternal separation compared to saline-treated controls (a). Representative traces are shown in b. ${ }^{*}$ is significantly different than saline-treated controls. $n=12$ per group

difference in body weight between saline-treated or Poly I:Ctreated mothers (Supplementary Figure 1C; $n=2$ rats/group).

\section{Cell Numbers}

To determine whether Poly I:C animals had a reduction in PV cells in the MPFC and whether the number of PV cells was increased by the cell transplants, we used immunohistochemistry. Consistent with other animal models of autism [11] and with post-mortem studies of people with autism [13,14], we found that prenatal Poly I:C exposure causes a reduction in the number of PV-positive cells in the mPFC (Fig. 2a, b; saline/dead cells $=15.23 \pm 1.26$ cells per $250 \mu^{2}$, Poly I:C/dead cells $=10.19 \pm 1.26$ cells per $250 \mathrm{~mm}^{2}$; Holm-Sidak $t=2.84, p<0.05, n=4-7$ rats/group). Furthermore, we also observed a significant increase in the number of PVpositive cells in the MPFC in both saline-treated and Poly I:Ctreated rats that received cell transplants (Fig. $2 \mathrm{a}$, b; saline/PV cells $=19.25 \pm 1.67$ cells per $250 \mathrm{~mm}^{2}$, Poly $\mathrm{l}: \mathrm{C} / \mathrm{PV}$ cells $=20.32 \pm 1.49$ cells per $250 \mathrm{~mm}^{2}$; Holm-Sidak $t=4.97, p<0.05, n=4-7$ rats per group).

Using electrophysiology and immunohistochemistry, we and others have shown previously that this stem cell differentiation protocol produces an enriched population of PV-positive interneurons that survive after transplantation into the somatosensory cortex [27] or the ventral hippocampus [28]. In the current experiments, we used dual-fluorescence immunohistochemistry to confirm that in the mPFC, the transplanted cells survived and differentiated into PV-positive interneurons (Fig. 2c-f). GFPpositive cells were observed throughout the MPFC (approximately from 4.68 to $3.00 \mathrm{~mm}$ anterior to Bregma; Fig. 2c). The majority of transplanted cells differentiated into PV-positive interneurons and there was no difference in the percentage of transplanted cells that express PV between saline- and Poly I:C-treated animals (Fig. 2d; Saline $=63.4 \pm 3.19$ percent of GFP-positive cells also expressed PV; Poly I:C $=56 \pm 5.0$ percent; $t_{(8)}=1.253, p=0.25, n$ $=5$ rats/group). Furthermore, there was no difference in the percentage of PV-positive cells that expressed GFP between saline-treated and Poly I:C-treated rats (Fig. 2e; Saline $=41.4 \pm 4.43$ percent of PV-positive cells also expressed GFP; Poly I:C $=38.2 \pm$ 4.8 percent; $t_{(8)}=0.49, p=0.64, n=5$ rats/group). One might expect that the proportion of double-labeled PV-positive and GFPpositive interneurons should be higher in the Poly I:C-treated animals due to the lower number PV-positive cells in this group at baseline. This was not the case, likely due to the highly heterogeneous distribution of the transplanted cells. Figure $2 f$ depicts a representative transplanted cell that expresses both GFP and PV.

\section{Ultrasonic Vocalizations}

To model the communication deficits that define autism, we recorded USVs in postnatal day 8 pups after maternal separation. We found that prenatal Poly I:C exposure produces an autism-like deficit in communication. Specifically, Poly I:C pups emit fewer ultrasonic vocalizations compared to saline-treated controls (Fig. 3a,b; Saline $=24.06 \pm 5.95$ USVs/minute, Poly I:C $=4.33 \pm$ 1.58 USVs/minute; $t_{(22)}=3.202, p<0.05, n=12$ ).

\section{Social Interaction}

The social interaction test was used to model social deficits, which are a core feature of autism. Poly I:C animals that received dead cell transplants show a trend to spend less time engaged in social interactions compared to saline-treated controls (Fig. 4; saline/ dead cells $=145.13 \pm 9.85 \mathrm{~s}$, Poly I:C/dead cells $=127.11 \pm 9.28 \mathrm{~s}$ ) Although transplantation of PV-positive cells into the mPFC had no effect in saline-treated animals, it produced a significant increase in social interaction time in the Poly $\mathrm{I}: \mathrm{C}$ rats that restored social interaction to a level consistent with controls (Fig. 4; saline/ PV cells $=153.00 \pm 11.37 \mathrm{~s}$, Poly I:C/PV cells $=155.11 \pm 9.28 \mathrm{~s}$; Holm-Sidak: $t=2.133, p=0.042$ ), suggesting that PV cell transplants may be an effective treatment strategy for the social deficits that characterize autism. There were no significant differences in 
number of USVs emitted during the social interaction test (Supplementary Figure 2).

Attentional Set-shifting

People with autism also demonstrate characteristic cognitive deficits including rigid, inflexible patterns of thought and behavior

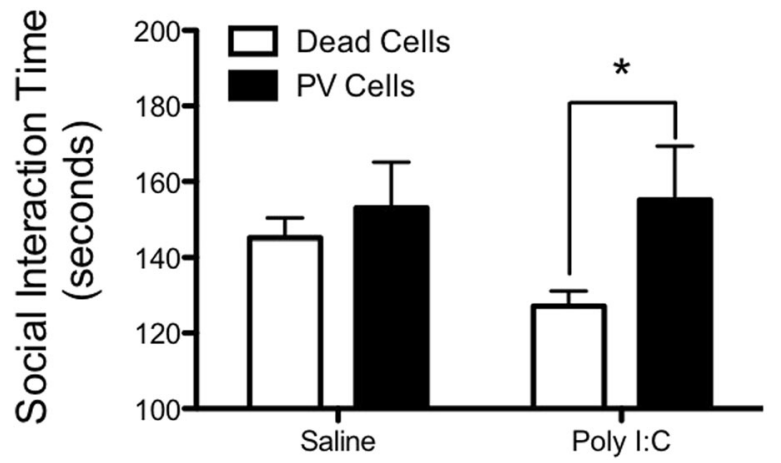

Fig. 3 Interneuron transplants alleviate deficits in social interaction in Poly I:C-treated animals. Rats that were exposed to Poly $\mathrm{I}: \mathrm{C}$ on gestational day 12 show a reduction in social interaction time compared to saline-treated controls. PV-positive interneuron transplants into the mPFC increase social interaction time in Poly I:Ctreated rats. * is significantly different than dead cell controls. $n=$ 6-9 per group
[38]. We used the attentional set-shifting test to measure two forms of cognitive flexibility that are disrupted in autism. First, we found that like autistic people [38], rats exposed to Poly I:C in utero show deficits in reversal learning (Fig. 1c; saline/dead cells $=$ $10.8 \pm 2.6$ trials to meet criterion, Poly I:C/dead cells $=25.167 \pm$ 2.381 trials; Holm-Sidak: $t=3.603, p=0.001$ ). In saline-treated animals, PV-positive transplants into the mPFC also impaired reversal learning (Fig. 1C; saline/PV cells $=19.17 \pm 2.38$ trials; Holm-Sidak: $t=2.328, p=0.028)$. However, in the Poly l:C animals, PV cell transplants actually improved performance (Fig. 1a; Poly I: C/PV cells $=15.50 \pm 2.06$ trials; Holm-Sidak: $t=2.717, p=0.012$ ). We also observed a significant difference between saline and Poly I:C rats that received cell transplants in the second reversal task. Cell transplants also significantly improved performance in the Poly I:C-treated animals compared to saline-treated rats that received the cell transplants (Fig. $1 \mathrm{~b}$; saline/dead cells $=7.83 \pm$ 0.92 trials, Poly I:C/dead cells $=9.88 \pm 0.80$ trials, saline/PV cells $=$ $10.17 \pm 0.93$ trials, Poly I:C/PV cells $=7.67 \pm 0.76$ trials; Holm-Sidak: $t=2.09, p=0.047$ ).

In addition, we measured extradimensional set shifting, another form of cognitive flexibility that is impaired in people with autism [39]. We found that Poly I:C animals displayed a trend $(p=0.05)$ for impaired extradimensional set-shifting compared to salinetreated controls (Fig. 1d; saline/dead cells $=14.00 \pm 2.48$ trials, Poly I:C/dead cells $=15.67 \pm 2.48$ trials; Holm-Sidak: $t=2.018, p=$ 0.054). Although they had no effect in the saline-treated animals, the PV cell transplants improved ED set-shifting in the Poly I:Ctreated rats (Fig. 1d; saline/PV cells $=15.67 \pm 2.48$ trials, Poly I:C/PV
A

\begin{tabular}{|c|c|c|c|c|}
\hline \multirow{2}{*}{$\begin{array}{c}\text { Discrimination } \\
\text { Stage }\end{array}$} & \multicolumn{2}{|c|}{ Dimensions } & \multicolumn{2}{|c|}{ Example Combinations } \\
\hline & Relevant & Irrelevant & $(+)$ & $(-)$ \\
\hline Simple (SD) & Odor & & Clove/Sawdust & Nutmeg/Sawdust \\
\hline Compound (CD) & Odor & Medium & $\begin{array}{l}\text { Clove/Raffia } \\
\text { Clove/Yarn }\end{array}$ & $\begin{array}{l}\text { Nutmeg/Yarn } \\
\text { Nutmeg/Raffia }\end{array}$ \\
\hline Reversal (RI) & Odor & Medium & $\begin{array}{l}\text { Nutmeg/Raffia } \\
\text { Nutmeg/ Metal Confetti }\end{array}$ & $\begin{array}{l}\text { Clove/Metal Confetti } \\
\text { Clove/Raffia }\end{array}$ \\
\hline $\begin{array}{l}\text { Intradimensional } \\
\text { Shift (ID) }\end{array}$ & Odor & Medium & $\begin{array}{l}\text { Rosemary/Wood Balls } \\
\text { Rosemary/Plastic Beads }\end{array}$ & $\begin{array}{l}\text { Cinnamon/Plastic Beads } \\
\text { Cinnamon/Wood Balls }\end{array}$ \\
\hline Reversal (R2) & Odor & Medium & $\begin{array}{l}\text { Cinnamon/Plastic Beads } \\
\text { Cinnamon/Wood Balls }\end{array}$ & $\begin{array}{l}\text { Rosemary/Wood Balls } \\
\text { Rosemary/Plastic Beads }\end{array}$ \\
\hline $\begin{array}{l}\text { Extradimensional } \\
\text { Shift (ED) }\end{array}$ & Medium & Odor & $\begin{array}{l}\text { Velvet/Citronella } \\
\text { Velvet/Thyme }\end{array}$ & $\begin{array}{l}\text { Crepe/Thyme } \\
\text { Crepe/Citronella }\end{array}$ \\
\hline
\end{tabular}

B

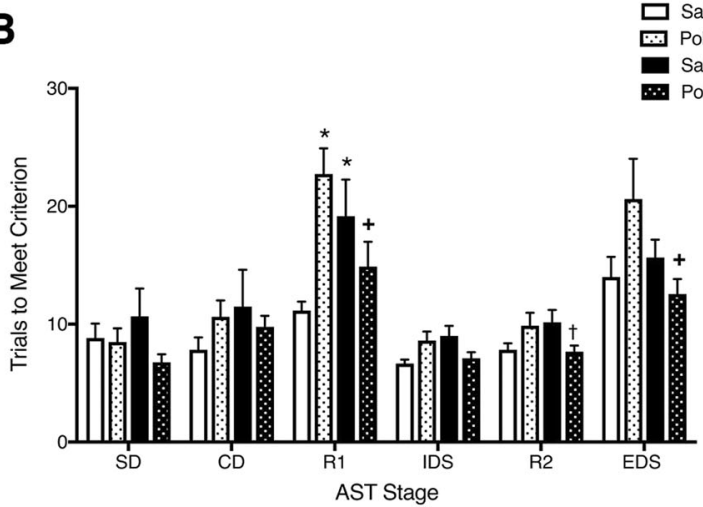

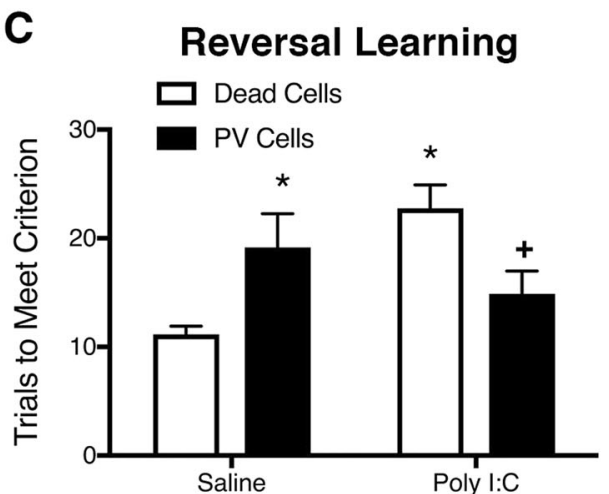

D Extradimensional set shifting

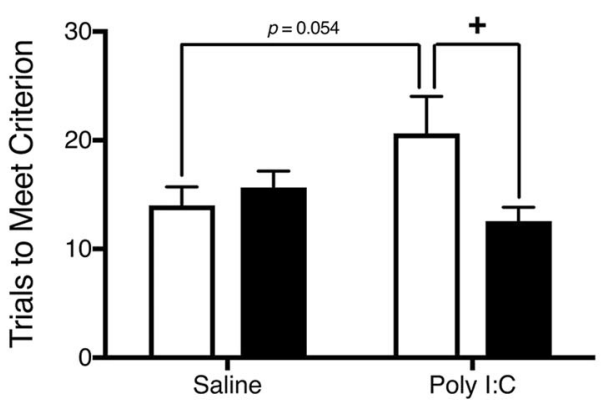

Fig. 4 Interneuron transplants improve cognitive flexibility in Poly I:C-treated animals. The stimuli used for each stage of the AST are presented in a. Rats that were exposed to Poly I:C on gestational day 12 show an increase in trials to meet criterion on the first reversal learning stage of the AST (c). Although interneuron transplants impaired reversal learning in control animals, PV-positive cells decreased trials to meet criterion in Poly I:C-treated rats (c). The increase in trials to meet criterion on the extradimensional set-shifting stage of the AST is completely abolished by PV-positive transplants into the MPFC (d). The other stages of the AST were not affected by Poly I:C or the cell transplants (b). * is significantly different than saline-treated animals that received dead cell transplants. + is significantly different than Poly l: C-treated animals that received dead cell transplants. $\dagger$ is significantly different than saline-treated animals that received PV cell transplants. $n=8-9$ per group 
cells $=12.56 \pm 2.03$ trials; Holm-Sidak: $t=2.732, p=0.011)$. We did not find differences on any other stage of the test (Fig. 1b), suggesting that the cognitive deficits specifically influence behavioral flexibility rather than motivation or learning. Excitingly, these findings suggest that PV cell transplants into the mPFC may improve cognitive flexibility in people with autism.

Prepulse Inhibition

Although autism and schizophrenia are two distinct disorders in humans, they display some overlapping symptoms (i.e. social withdrawal and cognitive dysfunction). Similarly, animal models of autism and schizophrenia display deficits in both social interaction

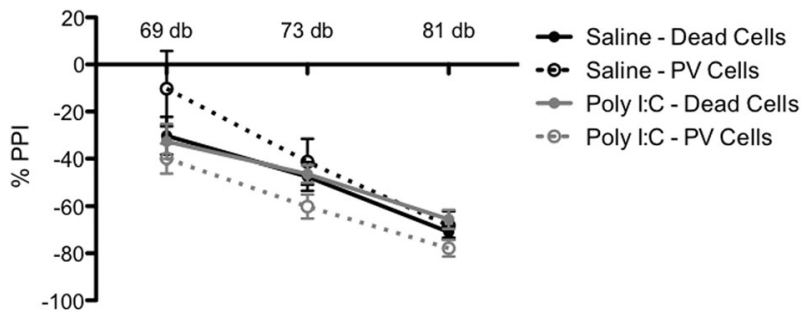

Fig. 5 Schizophrenia-like sensorimotor gating deficits are not affected by interneuron transplants. Prepulse inhibition of startle is not affected by Poly I:C exposure when compared to salinetreated control animals. PV interneuron transplants into the mPFC also did not dramatically alter prepulse inhibition in either the saline- or Poly I:C-treated rats. $n=9-13$ per group and cognition. However, deficits in prepulse inhibition of startle are one symptom observed in schizophrenia patients [40] but not autistic people [41, 42]; therefore, we measured PPI in the Poly I:C model to determine the specificity of interneuron transplants on autism- like deficits. There were no significant differences between groups in initial startle responses (data not shown). As expected, we observed an increase in the percentage of PPI as the prepulse volume increased (Fig. 5; Holm-Sidak: $69 \mathrm{~dB}$ vs. $81 \mathrm{~dB} t=8.862, p$ $<0.001 ; 73 \mathrm{~dB}$ vs $81 \mathrm{~dB} t=4.566, p<0.001 ; 69 \mathrm{~dB}$ vs $73 \mathrm{~dB} t=$ $4.295, p<0.001)$. However, there was no difference in PPI between saline- and Poly I:C-treated animals (Fig. 5; saline/dead cells/69 dB $=-30.25 \pm 6.56 \% \mathrm{PPI}$; saline $/$ dead cells $/ 73 \mathrm{~dB}=-47.42 \pm 6.56 \%$ $\mathrm{PPI}$; saline/dead cells $/ 81 \mathrm{~dB}=-70.92 \pm 6.56 \% \mathrm{PPI}$; Poly I:C/dead cells $/ 69 \mathrm{~dB}=-32.667 \pm 6.56 \% \quad \mathrm{PPI}$; Poly I:C/Dead cells $/ 73 \mathrm{~dB}$ $=-46.33 \pm 6.56 \%$ PPI; Poly I:C/dead cells $/ 81 \mathrm{~dB}=-65.58 \pm 6.56 \%$ PPI; Holm-Sidak: $t=0.249, p=0.804)$. Although the PV cell transplants in the mPFC had no effect on saline-treated animals at any of the volumes measured (Fig. 5; saline/PV cells/69 dB = $-10.22 \pm 7.57 \% \mathrm{PPI}$; saline/PV cells/73 $\mathrm{dB}=-41.22 \pm 7.57 \% \mathrm{PPI}$; saline/PV cells $/ 81 \mathrm{~dB}=-68.11 \pm 7.57 \% \mathrm{PPI}$; Holm-Sidak: $t=1.674$, $p=0.097$ ), the Poly I:C rats that received PV cell transplants were significantly different than the Poly I:C/Dead cell controls (Fig. 5; Poly I:C/PV cells $/ 69 \mathrm{~dB}=-39.85 \pm 6.3 \% \mathrm{PPl}$; Poly I:C/PV cells $/ 73 \mathrm{~dB}$ $=-60.15 \pm 6.3 \%$ PPI; Poly I:C/PV cells $/ 81 \mathrm{~dB}=-77.85 \pm 6.3 \% \mathrm{PPI}$; Holm-Sidak: $t=2.113, p=0.037)$. These results confirm that Poly I: $C$ exposure on gestational day 12 may produce an animal model with greater relevance to autism than schizophrenia but suggest that PV cell transplants in the MPFC may influence symptoms of both disorders.
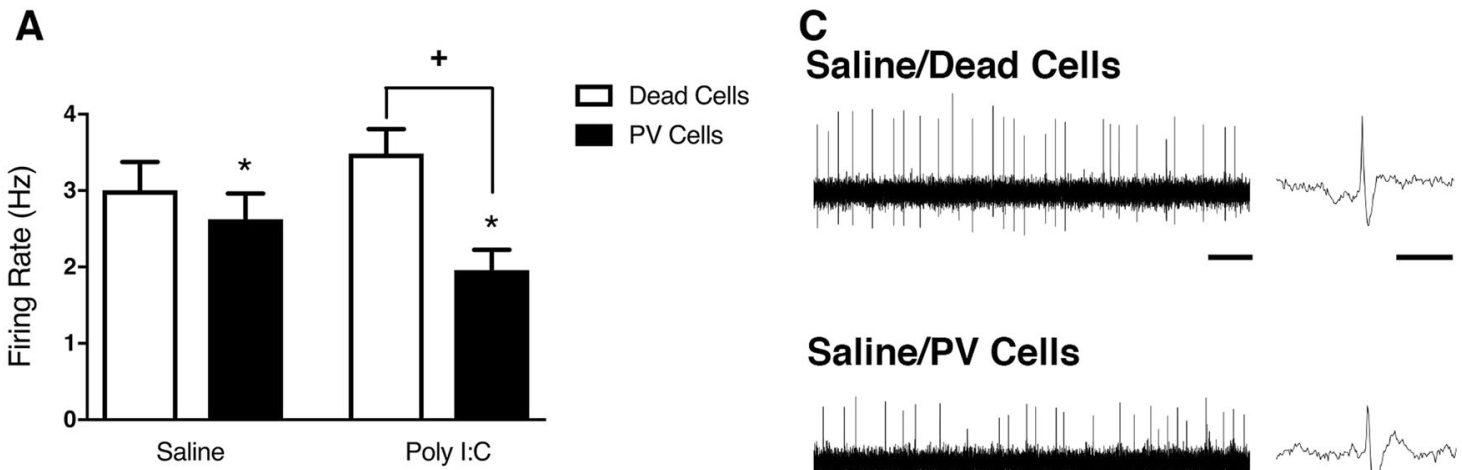

\section{Saline/PV Cells}
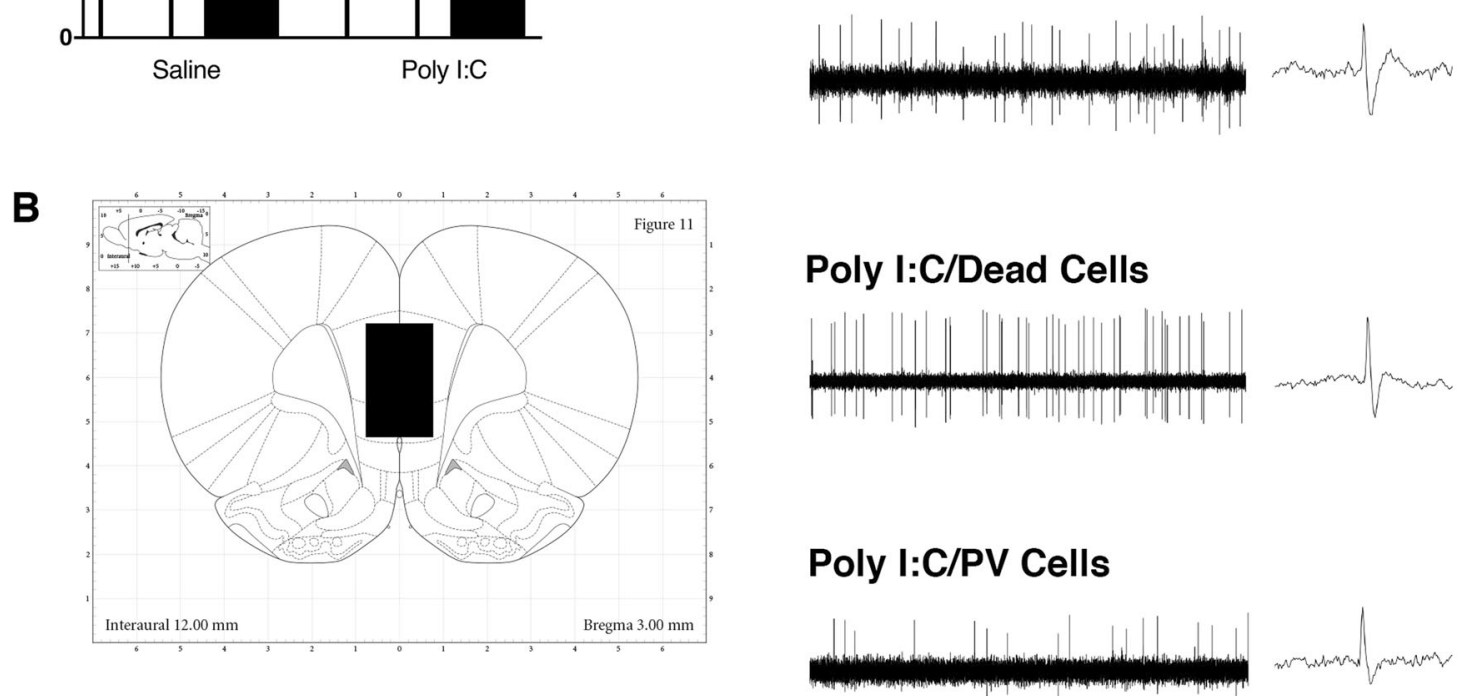

Fig. 6 Interneuron transplants normalize MPFC activity in Poly I:C-treated rats. The firing rate of putative pyramidal cells in the mPFC shows a trend to increase in Poly I:C-treated rats. Interneuron transplants decreased pyramidal cell firing rate in both saline and Poly I:C-treated animals (a). The recording area is shown shaded in b. Representative traces are depicted in $\mathbf{c} .{ }^{*}$ is significantly different than dead cell controls. + is significantly different than Poly I:C-treated rats that received dead cell transplants. Scale bars are $1 \mathrm{~s}$ and 5 msec, respectively. $n=53-60$ cells from 5 rats per group 
Electrophysiology

It has been suggested that autistic disorders may involve an increase in the ratio of excitation vs. inhibition, resulting in hyperexcitability in cortical circuits $[43,44]$. Therefore, we used in vivo extracellular recordings to measure the activity of putative pyramidal cells in the mPFC. We found that Poly $1: C$ treatment produces a modest but non-significant increase in pyramidal cell firing rate in the control animals (Fig. 6 saline/dead cells $=3.06 \pm$ $0.34 \mathrm{~Hz}$, Poly I:C/dead cells $=3.49 \pm 0.31 \mathrm{~Hz} ;$ Holm-Sidak: $t=0.913$, $p=0.362$ ). As expected, the PV cell transplants produced a significant decrease in pyramidal cell firing rate in both saline and Poly I:C-treated animals (Fig. 6; saline/PV cells $=2.62 \pm .32 \mathrm{~Hz}$, Poly I:C/PV cells $=1.96 \pm .33 \mathrm{~Hz}$; Holm-Sidak: $t=3.0, p=0.003$ ), suggesting that the cell transplants integrate into the existing circuitry and influence mPFC activity.

\section{DISCUSSION}

In the current paper, we provide the first experimental evidence that restoring parvalbumin (PV)-interneuron function using embryonic stem cells can attenuate behavioral deficits in an animal model of autism.

In order to study a novel treatment strategy for autism, in the current experiments we used the Poly I:C model of autism. Specifically, injecting pregnant female dams with the viral mimetic, Poly I:C, on gestational day 12 produces autism-like deficits in offspring, including reduced USVs, social avoidance, and stereotyped or repetitive behaviors [45]. However, it should be noted that the Poly I:C model, as with many other autism models, shares multiple features with rodent models of schizophrenia [46, 47], including the behaviors tested in the current manuscript. This is not surprising, considering that maternal infection has also been associated with schizophrenia [48]. It has been suggested that the timing of the prenatal infection may influence the resulting symptoms in offspring [49]. For example, in humans, deficits in PPI are one symptom observed in schizophrenia patients [40] but not autistic people [41, 42]. In line with our results, others have found that Poly I:C exposure early in gestation does not produce deficits in PPI $[50,51]$, while exposure later in pregnancy can impair PPI $[52,53]$. Conversely, deficits in communication are one of the core features of autism but not present in schizophrenia patients. As we and others have demonstrated, Poly $\mathrm{I}: \mathrm{C}$ exposure early in gestation produces a reduction in ultrasonic vocalizations [54]. Interestingly, Poly I:C exposure later in pregnancy actually increased vocalizations [55]. These results suggest that although it is difficult to completely separate animal models of schizophrenia and autism, Poly I:C administration specifically at gestational day 12, may be more relevant for autism than schizophrenia. Regardless, our findings that PV transplants into the mPFC alleviate schizophrenia-like and autism-like deficits in social interaction and cognitive function are in line with the Research Domain Criteria (RDoC) initiative, which was developed to provide a new classification framework for psychiatric disorders [56]. Because many mental health disorders, including autism and schizophrenia, display overlapping symptoms, the goal of RDoC is to provide a more comprehensive understanding of the molecules and circuits involved in discrete dimensions of psychiatric disease. Our results indeed have relevance for schizophrenia, but by targeting the mPFC specifically and by using a model that more closely resembles autism, we believe that our results have important implications in the treatment of autism as well.

People with autism present with deficits in communication. To confirm that the Poly I:C model recapitulated these communication deficits, we measured USVs after maternal separation. We found that pups from Poly I:C mothers emitted significantly fewer USVs than saline control pups. Although we are aware that it is difficult to accurately model the complexities of human communication in a rat, USVs emitted by pups after maternal separation are thought to serve as an important early form of communication. Indeed, these calls are the required stimulus for mothers to search and retrieve isolated pups and reduced USVs after maternal separation have been observed across rodent models of autism [57]. It is possible, however, that the reduction in USVs may be a result of altered maternal care by Poly I:C mothers. Indeed, others have shown that Poly $\mathrm{I}: \mathrm{C}$ exposure in mice can decrease licking/ grooming behavior [58, 59]. In the current experiments, we monitored the sickness response in the pregnant dams. We found that Poly I:C treatment caused a slight change in body temperature and food intake in the hours after the injection. Importantly, within $48 \mathrm{~h}$ of the injection, there was no difference in temperature, food intake, or body weight between the Poly I:Ctreated and saline-treated dams, suggesting that the sickness response had resolved by the time the pups were born. Further, others have shown that Poly I:C offspring cross-fostered with saline-treated mothers show similar behavioral deficits to those raised by Poly I:C-treated dams [59-61], suggesting that maternal care is not responsible for the autism-like behaviors observed in offspring. One major limitation of the USV results is that at the time point of testing (PND 8), the animals had not yet received the interneuron transplants. Furthermore, USVs were recorded during adult social interactions (Supplementary Figure 2) but the Poly I:C rats showed no deficits relative to control animals, making it difficult to interpret the ability of PV transplants to alleviate communication deficits.

In the current experiments, we demonstrate that altering the E/I ratio by transplanting PV-positive interneurons into the mPFC increases social interaction time in the Poly I:C model of autism. Autistic people demonstrate impairments in social functioning, including difficulty initiating social interactions and developing relationships, lack of interest in the emotions of others, and a lack of interest in sharing common interests or enjoyment with others [62]. Although rats are highly social species, our results are limited by the inability to adequately model the complexity of human social interactions. Others have consistently demonstrated that prenatal exposure to Poly I:C decreases social interaction time [63]. In the current experiments, we also found that Poly I:C-treated animals show a trend toward reduced social interaction time compared to saline-treated controls, although this effect was not significant. It is possible that the current results, although qualitatively similar to experiments from other laboratories, are less robust due to the severity of the MPFC manipulations in control rats. Indeed, the dead cell transplants may have produced subtle deficits in saline-treated rats, highlighting the importance of using the appropriate controls. However, our findings are in line with previous studies demonstrating that GABAergic signaling influences social function. For example, systemic administration of $G_{A B A_{A}}$ agonists increase social interaction time while antagonists decrease social interaction, although these effects may be secondary to changes in anxiety [64, 65]. In juvenile mice, PV knockdown or knockout reduces social interaction time [12]. In a more recent study, Yizhar et al [16] found that disrupting the excitation/inhibition (E/l) balance by selectively activating pyramidal cells in the MPFC using optogenetics, produces a deficit in social interaction. Interestingly, this deficit was reversed when the E/I balance was restored by simultaneously activating inhibitory interneurons [16]. Furthermore, restoring the $E / I$ balance in the mPFC by either optogenetically activating inhibitory interneurons or by inactivating pyramidal cells can improve social interaction deficits in a mouse model of autism [66].

Although our experiments focused on the mPFC, many other brain regions have been implicated in rodent social interaction, including the amygdala, hippocampus and ventral tegmental area (VTA) [65]. We have shown previously that PV interneuron transplants in the ventral hippocampus can increase social interaction time in a rodent model of schizophrenia [28]. However, this result is likely associated with the strong reciprocal 
connections between the ventral hippocampus and mPFC [67]. Similarly, the ventral tegmental area has also been implicated in social interaction. Dopamine cells in the VTA are active during social interactions [68], and decreasing dopamine release has been shown to decrease interaction time [68]. Given that dopamine cell activity is regulated by the MPFC [69], it is possible that the changes in social interaction we observed were due to direct effects of the interneuron transplants on mPFC function or through the ability of the MPFC to regulate other brain regions involved in social behaviors [62].

In the current experiments, we also provide evidence that interneuron transplants may effectively reduce stereotyped patterns of behavior, another core feature of autism. We used the attentional set-shifting test to measure two forms of behavioral flexibility: reversal learning and extradimensional setshifting. People with autism show deficits in both reversal learning and attentional set-shifting on the CANTAB $[38,39]$ and in the current experiments we found that Poly I:C-treated animals also show deficits in both forms of cognitive flexibility. Excitingly, interneuron transplants into the MPFC attenuate deficits in both reversal learning and extradimensional set-shifting. Reversal learning has been associated with orbitofrontal activity and subcortical dopamine function [70]. Therefore, the beneficial effects of the cell transplants may be due to the strong reciprocal connections between MPFC and OFC [71, 72] or through the ability of the MPFC to regulate dopamine cell firing in the VTA [69]. Interestingly, we found that in the saline-treated animals, PV transplants impaired reversal learning, which may result from the ability of the MPFC to regulate dopamine release from VTA cells. The effect of dopamine on cognitive function has been shown to fall on an inverted U- shaped curve [73], therefore, it is possible that the decrease in activity in the MPFC caused by the PV transplants would lead to less activation of the VTA [74], and ultimately dopamine levels would fall on the low end of the Ushaped curve leading to impaired cognitive function. Conversely, extradimensional set-shifting, like social interaction, depends on mPFC function [75]. Indeed, mPFC lesions cause specific deficits in extradimensional set-shifting without influencing other forms of cognitive flexibility, such as reversal learning [75]. The fact that mPFC disruptions can influence extradimensional set-shifting may explain why we did not see a significant effect of Poly I:C on this form of cognitive flexibility. In the current experiments, we found that interneuron transplants into the MPFC improve both forms of cognitive flexibility.

To our knowledge, the current experiments provide the first evidence that interneuron transplants, derived from embryonic stem cells, may be an effective treatment strategy for autism. Currently, cell-based therapies for the treatment of autism have focused on mesenchymal stem cells (MSCs). Indeed, two small open-label studies have shown symptom improvement in autistic people treated with MSCs [76, 77]. However, problems still exist with this highly controversial cell-based therapy [78] and the mechanisms of action of MSCs has not been completely elucidated.

Here, we reverse autism-like deficits in the Poly I:C model using embryonic stem cells that had been differentiated into an enriched population of PV-positive interneurons, allowing us to directly target a pathological mechanism of autism. It should be noted that there is some disagreement in the field as to whether there is an actual loss of cells or just a decrease in PV expression. However, we believe that either situation would result in a loss of PV cell function and that transplanting functional PV cells is a reasonable treatment strategy. Previously, we and others have demonstrated that these interneuron transplants not only express PV but also show a fast-spiking firing pattern characteristic of endogenous PV-positive interneurons $[27,28]$. Furthermore, we have shown previously that PV-positive transplants decrease firing rate of endogenous pyramidal cells [28], suggesting that the transplanted interneurons integrate into the circuitry and influence local circuit activity [4]. It should be noted that the Poly I:C-treated rats had fewer total PV-positive interneurons, suggesting that the proportion of PV-positive interneurons that were also GFP-positive should be higher in this group. However, this is not what we found. This discrepancy is likely due to the heterogenous distribution of the transplanted cells and our inability to perform three-dimensional analyses of the entire mPFC. Furthermore, we should recognize that although a majority of the transplanted cells differentiate into PV-positive interneurons, there is still a small percentage that do not express PV. In previous studies, we have found that the majority of these PV-negative cells express somatostatin [27, 28], which represents a distinct class of interneurons that may be contributing to the behavioral effects we observed. Regardless, by altering neuronal circuitry rather than temporarily increasing GABAergic signaling pharmacologically, interneuron transplants may provide a longer lasting treatment strategy. In the current experiments, the behavioral and electrophysiological effects were tested $>30$ days post transplantation. Although we have observed the presence of the cells for up to 6 months post transplantation (data not shown), future experiments should be performed to determine the duration of therapeutic effect.

Although cell-based therapies have long been hailed as the future of medicine, recent advances in stem cell biology have made this once sci-fi fantasy a reality. Methods to convert somatic cells into inducible pluripotent stem cells have been developed, allowing scientists to create virtually any cell type from non-fetal tissue. These advances, in addition to nullifying the moral argument against stem cell research, also opens the exciting possibility of treating people with autism with their own cells! Although many hurdles still exist before this therapy can be implemented in the clinic, we provide the first evidence that interneuron transplants, derived from embryonic stem cells, may be an effective treatment strategy for autism. Our findings demonstrate that transplantation of PV-positive interneurons into the mPFC in the Poly I:C model of autism improves deficits in social interaction and behavioral flexibility, two core features of autism that are severely debilitating but currently have no cure.

\section{ACKNOWLEDGEMENTS}

We would like to thank Dr. Stewart Anderson and Dr. Jennifer Tyson for their generous gift of the $\mathrm{J} 27$ mouse embryonic stem cell line containing dual reporters.

\section{FUNDING}

This work was supported by the Owens Foundation and by R01 MH090067 from the $\mathrm{NIH}$. Cell sorting was performed by the Flow Cytometry Shared Resource Facility, supported by UTHSCSA, NIH-NCI P30 CA054174-20 (CTRC at UTHSCSA) and UL1 TR001120 (CTSA grant).

\section{ADDITIONAL INFORMATION}

Supplementary information accompanies this paper at https://doi.org/10.1038/ s41386-018-0021-0.

Conflict of interest: The authors declare that they have no conflict of interest.

Publisher's note: Springer Nature remains neutral with regard to jurisdictional claims in published maps and institutional affiliations.

\section{REFERENCES}

1. Association AP (2013) Diagnostic and Statistical Manual of Mental Disorders: Dsm-5: Amer Psychiatric Pub Incorporated.

2. Baio J (2014) Prevalence of autism spectrum disorder among children aged 8 years -- Austism and developmental disabilities monitoring network, 11 sites, United States 2010. In: Morbidity and Mortality Weekly Report (Moran JS, ed), pp 1-22. Atlanta, GA. 
3. McPheeters ML, Warren Z, Sathe N, Bruzek JL, Krishnaswami S, Jerome RN, Veenstra-VanderWeele J. A systematic review of medical treatments for children with autism spectrum disorders. Pediatrics. 2011;127: e1312-e1321.

4. Coghlan S, Horder J, Inkster B, Mendez MA, Murphy DG, Nutt DJ. GABA system dysfunction in autism and related disorders: From synapse to symptoms. Neurosci Biobehav Rev. 2012;36:2044-55.

5. Ma DQ, Whitehead PL, Menold MM, Martin ER, Ashley-Koch AE, Mei H, Ritchie MD, DeLong GR, Abramson RK, Wright HH, Cuccaro ML, Hussman JP, Gilbert JR, Pericak-Vance MA. Identification of significant association and gene-gene interaction of GABA receptor subunit genes in autism. Am J Human Genet. 2005;77:377-88.

6. Delahanty RJ, Kang JQ, Brune CW, Kistner EO, Courchesne E, Cox NJ, Cook EH Jr., Macdonald RL, Sutcliffe JS. Maternal transmission of a rare GABRB3 signal peptide variant is associated with autism. Mol Psychiatry. 2011;16:86-96.

7. Blatt GJ, Fitzgerald CM, Guptill JT, Booker AB, Kemper TL, Bauman ML. Density and distribution of hippocampal neurotransmitter receptors in autism: an autoradiographic study. J Autism Dev Disord. 2001;31:537-43.

8. Mori T, Mori K, Fujii E, Toda Y, Miyazaki M, Harada M, Hashimoto T, Kagami S. Evaluation of the GABAergic nervous system in autistic brain: 1231-iomazenil SPECT study. Brain Dev. 2012;34:648-54.

9. Fatemi SH, Halt AR, Stary JM, Kanodia R, Schulz SC, Realmuto GR. Glutamic acid decarboxylase 65 and $67 \mathrm{kDa}$ proteins are reduced in autistic parietal and cerebellar cortices. Biol Psychiatry. 2002;52:805-10.

10. Harada M, Taki M, Nose A, Kubo H, Mori K, Nishitani H, Matsuda T. Non-invasive evaluation of the GABAergic/glutamatergic system in autistic patients observed by MEGA-editing proton MR spectroscopy using a clinical 3 tesla instrument. J Autism Dev Disord. 2011:41:447-54.

11. Gogolla N, LeBlanc JJ, Quast KB, Südhof TC, Fagiolini M, Hensch TK. Common circuit defect of excitatory-inhibitory balance in mouse models of autism. Neurodev Disord. 2009;1:172-81.

12. Wohr M, Orduz D, Gregory P, Moreno H, Khan U, Vorckel KJ, Wolfer DP, Welzl H, Gall D, Schiffmann SN, Schwaller B. Lack of parvalbumin in mice leads to behavioral deficits relevant to all human autism core symptoms and related neural morphofunctional abnormalities. Transl Psychiatry. 2015;5:e525.

13. Hashemi E, Ariza J, Rogers H, Noctor SC, Martínez-Cerdeño V. The number of parvalbumin-expressing interneurons is decreased in the medial prefrontal cortex in autism. Cereb Cortex. 2016;27:1931-43.

14. Zikopoulos B, Barbas $\mathrm{H}$. Altered neural connectivity in excitatory and inhibitory cortical circuits in autism. Front Human Neurosci. 2013;7:609.

15. Sohal VS, Zhang F, Yizhar O, Deisseroth K. Parvalbumin neurons and gamma rhythms enhance cortical circuit performance. Nature. 2009;459:698-702.

16. Yizhar $O$, Fenno LE, Prigge $M$, Schneider F, Davidson TJ, O/'Shea DJ, Sohal VS, Goshen I, Finkelstein J, Paz JT, Stehfest K, Fudim R, Ramakrishnan C, Huguenard JR, Hegemann P, Deisseroth K. Neocortical excitation/inhibition balance in information processing and social dysfunction. Nature. 2011;477:171-8.

17. Gandal MJ, Edgar JC, Ehrlichman RS, Mehta M, Roberts TPL, Siegel SJ. Validating Y oscillations and delayed auditory responses as translational biomarkers of autism. Biol Psychiatry. 2010;68:1100-6.

18. Orekhova EV, Stroganova TA, Nygren G, Tsetlin MM, Posikera IN, Gillberg C, Elam $M$. Excess of high frequency electroencephalogram oscillations in boys with autism. Biol Psychiatry. 2007;62:1022-9.

19. Amaral DG, Schumann CM, Nordahl CW. Neuroanatomy of autism. Trends Neurosci. 2008:31:137-45.

20. Dichter GS, Felder JN, Bodfish JW. Autism is characterized by dorsal anterior cingulate hyperactivation during social target detection. Soc Cogn Affect Neurosci. 2009;4:215-26.

21. Gomot M, Belmonte MK, Bullmore ET, Bernard FA, Baron-Cohen S. Brain hyperreactivity to auditory novel targets in children with high-functioning autism. Brain. 2008;131:2479-88.

22. Belmonte $M K$, Gomot M, Baron-Cohen S. Visual attention in autism families: 'unaffected' sibs share atypical frontal activation. J Child Psychol Psychiatry. 2010;51:259-76.

23. Cardin JA, Carlen M, Meletis K, Knoblich U, Zhang F, Deisseroth K, Tsai L-H, Moore $\mathrm{Cl}$. Driving fast-spiking cells induces gamma rhythm and controls sensory responses. Nature. 2009;459:663-7.

24. Wilson TW, Rojas DC, Reite ML, Teale PD, Rogers SJ. Children and adolescents with autism exhibit reduced MEG steady-state gamma responses. Biol Psychiatry. 2007;62:192-7.

25. Cho KK, Hoch R, Lee AT, Patel T, Rubenstein JL, Sohal VS. Gamma rhythms link prefrontal interneuron dysfunction with cognitive inflexibility in Dlx5/6+/- mice. Neuron. 2015;85:1332-43.

26. Tyson JA, Anderson SA. GABAergic interneuron transplants to study development and treat disease. Trends Neurosci. 2014;37:169-77.
27. Tyson JA, Goldberg EM, Maroof AM, Xu Q, Petros TJ, Anderson SA. Duration of culture and sonic hedgehog signaling differentially specify PV versus SST cortical interneuron fates from embryonic stem cells. Development. 2015;142:1267-78.

28. Donegan JJ, Tyson Jennifer A, Branch SY, Beckstead MJ, Anderson SA, Lodge DJ (2016) Stem cell derived interneuron transplants as a treatment for schizophrenia: preclinical validation in a rodent model. Mol Psychiatry. Mol Psychiatry. 2017;22:1492-1501

29. Atladóttir H, Thorsen P, Østergaard L, Schendel D, Lemcke S, Abdallah M, Parner E. Maternal infection requiring hospitalization during pregnancy and autism spectrum disorders. J Autism Dev Disord. 2010:40:1423-30.

30. Patterson PH. Maternal infection and immune involvement in autism. Trends Mol Med. 2011;17:389-94.

31. Perez SM, Lodge DJ. Hippocampal interneuron transplants reverse aberrant dopamine system function and behavior in a rodent model of schizophrenia. Mol Psychiatry. 2013;18:1193-8.

32. Lord C, Risi S, Lambrecht L, Cook EH Jr., Leventhal BL, DiLavore PC, Pickles A, Rutter M. The autism diagnostic observation schedule-generic: a standard measure of social and communication deficits associated with the spectrum of autism. J Autism Dev Disord. 2000;30:205-23.

33. Hofer, M. A., Shair, H. N. and Brunelli, S. A. 2002. Ultrasonic Vocalizations in Rat and Mouse Pups. Current Protocols in Neuroscience. 17:8.14 8.14.1-8.14.16.

34. Cecchi $M$, Khoshbouei $H$, Morilak DA. Modulatory effects of norepinephrine, acting on alpha1 receptors in the central nucleus of the amygdala, on behavioral and neuroendocrine responses to acute immobilization stress. Neuropharmacology. 2002;43:1139-47.

35. Lapiz MD, Morilak DA. Noradrenergic modulation of cognitive function in rat medial prefrontal cortex as measured by attentional set shifting capability. Neuroscience. 2006;137:1039-49.

36. Homayoun $\mathrm{H}$, Moghaddam B. NMDA Receptor Hypofunction Produces Opposite Effects on Prefrontal Cortex Interneurons and Pyramidal Neurons. J Neurosci. 2007;27:11496-11500.

37. Paxinos G, Watson C. The rat brain in stereotaxic coordinates. 6 Edition. London, UK: Elsevier; 2006.

38. Hughes C, Russell J, Robbins TW. Evidence for executive dysfunction in autism. Neuropsychologia. 1994;32:477-92.

39. Ozonoff S, Cook I, Coon H, Dawson G, Joseph RM, Klin A, McMahon WM Minshew N, Munson JA, Pennington BF, Rogers SJ, Spence MA, Tager-Flusberg H, Volkmar FR, Wrathall D. Performance on cambridge neuropsychological test automated battery subtests sensitive to frontal lobe function in people with autistic disorder: evidence from the collaborative programs of excellence in autism network. J Autism Dev Disord. 2004;34:139-50.

40. Grillon C, Ameli R, Charney DS, Krystal J, Braff D. Startle gating deficits occur across prepulse intensities in schizophrenic patients. Biol Psychiatry. 1992;32:939-43.

41. Kohl S, Wolters C, Gruendler TOJ, Vogeley K, Klosterkötter J, Kuhn J. Prepulse inhibition of the acoustic startle reflex in high functioning autism. PLoS ONE. 2014;9:e92372.

42. Takahashi H, Komatsu S, Nakahachi T, Ogino K, Kamio Y. Relationship of the acoustic startle response and its modulation to emotional and behavioral problems in typical development children and those with autism spectrum disorders. J Autism Dev Disord. 2016:46:534-43.

43. Nelson Sacha B, Valakh V. Excitatory/inhibitory balance and circuit homeostasis in autism spectrum disorders. Neuron. 2015;87:684-98.

44. Rubenstein JLR, Merzenich MM. Model of autism: increased ratio of excitation/ inhibition in key neural systems. Genes Brain Behav. 2003;2:255-67.

45. Patterson PH. Maternal infection and autism. Brain Behav Immun. 2012;26:393.

46. Lodge DJ, Grace AA. Gestational methylazoxymethanol acetate administration: a developmental disruption model of schizophrenia. Behav Brain Res. 2009;204:306-12.

47. Neill JC, Barnes S, Cook S, Grayson B, Idris NF, McLean SL, Snigdha S, Rajagopal L, Harte MK. Animal models of cognitive dysfunction and negative symptoms of schizophrenia: focus on NMDA receptor antagonism. Pharmacol Ther. 2010;128:419-32.

48. Brown AS. Exposure to prenatal infection and risk of schizophrenia. Front Psychiatry. 2011;2:63

49. Brown AS, Derkits EJ. Prenatal infection and schizophrenia: a review of epidemiologic and translational studies. Am J Psychiatry. 2010;167:261-80.

50. Eßlinger $M$, Wachholz S, Manitz M-P, Plümper J, Sommer R, Juckel G, Friebe A. Schizophrenia associated sensory gating deficits develop after adolescent microglia activation. Brain Behav Immun. 2016;58:99-106.

51. Fortier $M-E$, Luheshi GN, Boksa P. Effects of prenatal infection on prepulse inhibition in the rat depend on the nature of the infectious agent and the stage of pregnancy. Behav Brain Res. 2007;181:270-7. 
52. Zhang $Z$, van Praag $H$. Maternal immune activation differentially impacts mature and adult-born hippocampal neurons in male mice. Brain Behav Immun. 2015;45:60-70.

53. Bikovsky L, Hadar R, Soto-Montenegro ML, Klein J, Weiner I, Desco M, Pascau J, Winter C, Hamani C. Deep brain stimulation improves behavior and modulates neural circuits in a rodent model of schizophrenia. Exp Neurol. 2016;283:142-50.

54. Hsiao Elaine $Y$, McBride Sara W, Hsien S, Sharon G, Hyde Embriette R, McCue T, Codelli Julian A, Chow J, Reisman Sarah E, Petrosino Joseph F, Patterson Paul H, Mazmanian Sarkis K. Microbiota modulate behavioral and physiological abnormalities associated with neurodevelopmental disorders. Cell. 2013;155:1451-63.

55. Yee N, Schwarting RKW, Fuchs E, Wöhr M. Increased affective ultrasonic communication during fear learning in adult male rats exposed to maternal immune activation. J Psychiatr Res. 2012;46:1199-205.

56. Insel T, Cuthbert B, Garvey M, Heinssen R, Pine DS, Quinn K, Sanislow C, Wang P. Research Domain Criteria (RDoC): Toward a new classification framework for research on mental disorders. Am J Psychiatry. 2010;167:748-51.

57. Wöhr M, Scattoni ML. Behavioural methods used in rodent models of autism spectrum disorders: Current standards and new developments. Behav Brain Res. 2013;251:5-17.

58. Ronovsky M, Berger S, Zambon A, Reisinger SN, Horvath O, Pollak A, Lindtner C, Berger A, Pollak DD. Maternal immune activation transgenerationally modulates maternal care and offspring depression-like behavior. Brain Behav Immun. 2017;63:127-36.

59. Schwendener S, Meyer U, Feldon J. Deficient maternal care resulting from immunological stress during pregnancy is associated with a sex-dependent enhancement of conditioned fear in the offspring. J Neurodev Disord. 2009;1:15-32.

60. Meyer U, Nyffeler M, Schwendener S, Knuesel I, Yee BK, Feldon J. Relative prenatal and postnatal maternal contributions to schizophrenia-related neurochemical dysfunction after in utero immune challenge. Neuropsychopharmacology. 2007;33:441-56.

61. Richetto J, Calabrese F, Meyer U, Riva MA. Prenatal versus postnatal maternal factors in the development of infection-induced working memory impairments in mice. Brain Behav Immun. 2013;33:190-200.

62. Barak B, Feng G. Neurobiology of social behavior abnormalities in autism and Williams syndrome. Nat Neurosci. 2016;19:647-55.

63. Smith SEP, Li J, Garbett K, Mirnics K, Patterson PH. Maternal immune activation alters fetal brain development through interleukin-6. J Neurosci. 2007;27:10695-702.
64. Corbett R, Fielding S, Cornfeldt M, Dunn RW. GABAmimetic agents display anxiolytic-like effects in the social interaction and elevated plus maze procedures. Psychopharmacol (Berl). 1991;104:312-6.

65. File SE, Seth P. A review of 25 years of the social interaction test. Eur J Pharmacol. 2003;463:35-53.

66. Selimbeyoglu A, Kim CK, Inoue M, Lee SY, Hong ASO, Kauvar I, Ramakrishnan C, Fenno LE, Davidson TJ, Wright M, Deisseroth K (2017) Modulation of prefrontal cortex excitation/inhibition balance rescues social behavior in CNTNAP2-deficient mice. Sci Transl Med 9. pii: eaah6733

67. Rosene DL, Hoesen GWV. Hippocampal efferents reach widespread areas of cerebral cortex and amygdala in the rhesus monkey. Science. 1977;198:315-7.

68. Gunaydin Lisa A, Grosenick L, Finkelstein Joel C, Kauvar Isaac V, Fenno Lief E, Adhikari A, Lammel S, Mirzabekov Julie J, Airan Raag D, Zalocusky Kelly A, Tye Kay M, Anikeeva P, Malenka Robert C, Deisseroth K. Natural neural projection dynamics underlying social behavior. Cell. 2014;157:1535-51.

69. Lodge DJ. The medial prefrontal and orbitofrontal cortices differentially regulate dopamine system function. Neuropsychopharmacology. 2011;36:1227-36.

70. Kehagia AA, Murray GK, Robbins TW. Learning and cognitive flexibility: frontostriatal function and monoaminergic modulation. Curr Opin Neurobiol. 2010;20:199-204.

71. Cavada C, Compañy T, Tejedor J, Cruz-Rizzolo RJ, Reinoso-Suárez F. The anatomical connections of the macaque monkey orbitofrontal cortex. A Rev Cereb Cortex. 2000;10:220-42.

72. Kringelbach ML. The human orbitofrontal cortex: Linking reward to hedonic experience. Nat Rev: Neurosci. 2005;6:691-702.

73. Arnsten AFT. Stress signalling pathways that impair prefrontal cortex structure and function. Nat Rev: Neurosci. 2009;10:410-22.

74. Lodge DJ, Grace AA. Hippocampal dysregulation of dopamine system function and the pathophysiology of schizophrenia. Trends Pharmacol Sci. 2011;32:507-13.

75. Birrell JM, Brown VJ. Medial frontal cortex mediates perceptual attentional set shifting in the rat. J Neurosci. 2000;20:4320-4.

76. Lv YT, Zhang Y, Liu M, Qiuwaxi JN, Ashwood P, Cho SC, Huan Y, Ge RC, Chen XW, Wang ZJ, Kim BJ, Hu X. Transplantation of human cord blood mononuclear cells and umbilical cord-derived mesenchymal stem cells in autism. J Transl Med. 2013;11:196.

77. Sharma A, Gokulchandran N, Sane H, Nagrajan A, Paranjape A, Kulkarni P, Shetty A, Mishra P, Kali M, Biju H, Badhe P. Autologous bone marrow mononuclear cell therapy for autism: an open label proof of concept study. Stem Cells Int. 2013;2013:623875.

78. Siniscalco D, Bradstreet JJ, Sych N, Antonucci N. Mesenchymal stem cells in treating autism: novel insights. World J Stem Cells. 2014;6:173-8. 